\title{
Geoinformatics and Atmospheric Science: Introduction
}

\author{
Tomasz Niedzielski ${ }^{1}$ and Krzysztof Migata ${ }^{1}$
}

Numerous products of meteorological analyses are nowadays required to be available in real or near real time. For instance, this concerns: monitoring networks designed to measure weather parameters or air quality indices, numerical weather predictions or air quality forecasts. In addition, the dynamics of the atmosphere and its permanent assessment and prediction influence water management. Therefore, investigations into hydrologic phenomena or ocean dynamics have to be enhanced by rapidly available meteorological products or-e.g., in the case of ocean-atmosphere interactions-the products themselves may make use of ocean-related real- or nearreal-time analyses. In particular, applications of weather forecasts go beyond meteorology and are important in environmental protection activities as well as social and economic analyses.

The aforementioned tasks cannot be efficiently carried out without the use of recent advances in geoinformatics, the scope of which is to provide broadly understood geosciences with information technologies and infrastructure. In particular, geoinformatics - a modern discipline that makes use of geographic information systems, remote sensing, computer science as well as physical and empirical modelling methods-offers computational tools which are suitable for modelling spatial- or spatiotemporal phenomena. Not only remotely sensed data but also in situ measurements can be handled by geoinformation tools, for instance to produce gridded data products. The objective of this special issue of Pure and Applied Geophysics on "Geoinformatics

1 Faculty of Earth Sciences and Environmental Management, Institute of Geography and Regional Development, University of Wrocław, pl. Uniwersytecki 1, 50-137 Wrocław, Poland. E-mail: tomasz.niedzielski@uwr.edu.pl; krzysztof.migala@uwr.edu.pl and Atmospheric Science" is to present recent geoinformatics-based tools to solve atmospheric and water-related problems. A particular emphasis is put on geophysical problems which are associated with physics of atmosphere, meteorology, hydrology, ocean dynamics or climatology.

Associated with the special issue was the conference, the 22nd Cartographic School "Geoinformatics and Atmospheric Science" held in Wałbrzych-Książ (Poland) on 6-9 May 2014. Several papers presented at the 22nd Cartographic School are published in the special issue, but the selection of the papers has been successfully enriched by external submissions.

Many papers published in the special issue focus on Poland, the area which represents the European transitional zone between oceanic and continental features of the mid-latitude climate. A meaningful interseasonal and weather-related variability of the features within the zone in question causes difficulties in accurate modelling of the spatial distribution of atmospheric processes and phenomena. Improving skillfulness of the spatial modelling approaches for the said area, in particular operating in real time, remains one of the most important applications of geoinformatics in the field of atmospheric science.

Two papers of the special issue focus on oceanic problems. The work of Vaid (2017) aims to present the analysis of the biweekly oscillation in sea surface temperature (SST) changes in the South China Sea, with a particular emphasis put on its relations with the Western North Pacific Summer Monsoon. The author uses SST data acquired by the microwave imager (TMI) of the Tropical Rainfall Measuring Mission (TRMM) as well as the satellite-observed rainfall measurements and heat flux data. It is found that ocean-to-atmosphere processes induced by the biweekly oscillation in SST variations in the South China Sea enhance both sea level pressure and 
surface shortwave radiation flux, during the summer monsoon. The study confirms the usefulness of geoinformatics (here, remote sensing data and geocomputation) to solve the problems of oceanatmosphere interactions. Yet another analysis of monsoon circulation, focused on the Indian Summer Monsoon, is offered by Yadav and Singh (2017). The authors concentrate on two specific years, 2013 and 2014, in which the monsoon dynamics differed significantly (2013 - timely onset and rapid progression; 2014-delayed onset and slow progression). It is found that those differences were controlled by the strength of persistent convection over the north equatorial Indian Ocean in May which implied several consequences for the atmospheric circulation over the study area. In the context of the scope of the special issue, an emphasis should be placed on geoinformatics tools which are used to carry out the analyses-among others the authors utilised the Ferret software (visualisation and analysis environment dedicated for meteorologists and oceanographers) and the NCL environment (language for research data processing and visualisation).

The special issue consists of a few papers on mesoscale numerical weather prediction, carried out using the Weather Research and Forecasting (WRF) model. The WRF model is a large, computationally efficient platform dedicated for forecasting the dynamics of various elements of the atmosphere. Wałaszek et al. (2017) use the WRF model to simulate the cloud cover over Poland in the case study for a specific period when ozone concentration was very high. Numerous microphysics parameterization schemes are used, and the authors arrive at the conclusion that the Morrison Double-Moment microphysics is recommended for the scrutinised episode. A different application of the WRF model for Poland is presented by Kryza et al. (2017) and Ojrzyńska et al. (2017) who makes use of dynamical downscaling of four meteorological variables (air temperature, relative humidity, wind speed, wind direction). The statistical assessment of modelling skills shows a particularly good agreement between air temperature simulations and measured data (Kryza et al. 2017). The calibrated model is used by Ojrzyńska et al. (2017) to classify macrotypes of atmospheric circulation in an automatic fashion. The
WRF model may also be used to simulate and predict air quality, as presented by Werner et al. (2017) who utilise its version with chemistry known as WRFChem. The authors apply the model in question to check the impact of direct and indirect feedback effects of aerosols on simulations of $\mathrm{PM}_{10}$ concentration and the selected meteorological variables.

Yet another example of physically-based modelling of meteorological variables is presented by Jancewicz and Szymanowski (2017) who make use of the computational fluid dynamics (CFD) diagnostic solver Canyon, included in WindStation software, for the purpose of simulating wind field in mountainous terrain. The CFD solution is based on: mass conservation, momentum conservation and energy conservation. The authors concentrate on the Śnieżnik Massif in southwestern Poland and perform a wind field reconstruction experiment for a few specific episodes. The objective of the work is to quantify the impact of surface roughness computed on a basis of different source spatial data on the output wind field simulations. It is found that the roughness based on LIDAR (Light Detection and Ranging) data, derived from the information on the complexity of relief without considering land cover characteristics, offers the acceptable wind field reconstruction.

Apart from the above-mentioned physically-based meteorological modelling, the special issue consists of two articles that utilise data-based (or empirical) models to simulate meteorological or climatological variables. The data-based models usually omit physical fundamentals that control a given phenomenon, but they extensively use data processing methods which aim to build models that associate inputs with outputs. Many geographic information systems and environments for scientific computing have such modelling tools implemented, and therefore the methods belong to the scope of geoinformatics. Szymanowski and Kryza (2017) present an extensive study on the use of mixed deterministic-stochastic models in modelling air temperature in Poland. The authors' main objective is to check if it is justified to incorporate as many explanatory variables as possible to improve the accuracy of air temperature modelling. They arrive at the conclusion that only first 1-3 environmental variables (elevation, location, distance 
from the sea) are meaningful. Deterministic and stochastic modelling may also be used for simulating climatological variables, as presented by Szymanowski et al. (2017). The authors focus on the Ewert's index which quantifies the continentality of climate. On the example of Poland, which is located on the contact of continental and oceanic climate forcing, Szymanowski et al. (2017) perform spatial interpolation of the index in question. They formulate recommendations on using specific interpolators, in particular in the context of possible automation of the procedure. A different approach for predicting localscale extreme weather phenomena is proposed by Walawender et al. (2017) who utilised the Favourable Meteorological Conditions (FMC) algorithms and several data-based statistical models. The authors aim to forecast thunderstorms, fog, glaze and rime, and their exercise uses a long time period (45 years) and concentrates on Poland. The paper serves as a methodological background for producing predictive maps, as presented in the Meteorological Hazard Atlas of Poland.

Since it is difficult to elaborate accurate prognoses of drought, which is associated with a longterm variability of the phenomenon, it is usually convenient to carry out drought risk assessment. Ruda et al. (2017) present a multi-stage approach for quantifying risk level, and illustrate it on the example area located in southeastern Czechia. A particular emphasis is put on a role of landscape complexity in drought development. It is found that even within a relatively small area, the risk level varies significantly in space.

A natural area of application of atmospheric products and reports is hydrology. Two papers published in the special issue offer case studies on applications of geoinformation methods in hydrologic analyses, in particular in flood hazard assessment. Mentzafou et al. (2017) use the geographically weighted regression to classify the Evros river basin into areas of dissimilar flood hazard categories. A different approach is explored by Rutkowska et al. (2017) who presents the L-moment-based analysis for the upper Vistula river basin. The authors claim that the approach may be used to estimate flood quantiles at ungauged sites and therefore has a considerable potential for flood risk assessment studies.
Atmospheric processes are not only associated with oceanic and hydrologic phenomena, but also may have a significant influence on solid Earth. One of such impacts is the atmospheric mass loading which remains a part of the entire signal measured at reference stations of the Global Navigation Satellite System (GNSS). Peng et al. (2017) consider the time series of vertical GNSS coordinates of the selected reference stations located in China. One of the main findings is decomposition of the seasonal non-tectonic signal into terms which correspond to atmospheric and soil moisture mass loading. The GNSS observations and their processing belong to very important areas of geoinformatics, since they provide location data for the majority of geoscientific analyses.

\section{Acknowledgements}

Guest Editors would like to express sincere thanks to a few persons and organisations. In particular, we are grateful to Dr. Renata Dmowska, the Editor-in-Chief for topical issues and book reviews of Pure and Applied Geophysics, who kindly accepted the proposal of the special issue on "Geoinformatics and Atmospheric Science”. Dr. Dmowska's advice was very helpful and professional at all stages of the editorial work. We are also indebted to experts representing Birkhäuser/Springer Basel AG who kindly offered technical support. The members of Scientific Organising Committee and Local Organising Committee of the 22nd Cartographic School are also acknowledged. The conference was supported by Rector of the University of Wrocław, Section for Cartography of Polish Geographical Society and the Lower Silesian Marshal's Office. Special thanks should be given to all contributors who submitted their work to the special issue. We also wish to express our thanks to all reviewers who evaluated the manuscripts and provided the authors with valuable comments.

Open Access This article is distributed under the terms of the Creative Commons Attribution 4.0 International License (http:// creativecommons.org/licenses/by/4.0/), which permits unrestricted use, distribution, and reproduction in any medium, provided you give appropriate credit to the original author(s) and the source, 
provide a link to the Creative Commons license, and indicate if changes were made.

\section{REFERENCES}

Jancewicz, K., \& Szymanowski, M. (2017). The relevance of surface roughness data qualities in diagnostic modeling of wind velocity in complex terrain: a case study from the Śnieżnik Massif (SW Poland). Pure and Applied Geophysics. doi:10.1007/ s00024-016-1297-9.

Kryza, M., Wałaszek, K., Ojrzyńska, H., Szymanowski, M., Werner, M., \& Dore, A. J. (2017). High-resolution dynamical downscaling of ERA-interim using the WRF regional climate model for the area of Poland. Part 1: model configuration and statistical evaluation for the 1981-2010 period. Pure and Applied Geophysics. doi:10.1007/s00024-016-1272-5.

Mentzafou, A., Markogianni, V., \& Dimitriou, E. (2017). The use of geospatial technologies in flood hazard mapping and assessment: case study from River Evros. Pure and Applied Geophysics. doi:10.1007/s00024-016-1433-6.

Ojrzyńska, H., Kryza, M., Wałaszek, K., Szymanowski, M., Werner, M., \& Dore, A. J. (2017). High-resolution dynamical downscaling of ERA-interim using the WRF regional climate model for the Area of Poland. Part 2: model performance with respect to automatically derived circulation types. Pure and Applied Geophysics. doi:10.1007/s00024-016-1273-4.

Peng, W., Dai, W., Santerre, R., Cai, C., \& Kuang, C. (2017). GNSS vertical coordinate time series analysis using singlechannel independent component analysis method. Pure and Applied Geophysics. doi:10.1007/s00024-016-1309-9.

Ruda, A., Kolejka, J., \& Batelková, K. (2017). Geocomputation and spatial modelling for geographical drought risk assessment: a case study of the Hustopeče Area. Pure and Applied Geophysics: Czech Republic. doi:10.1007/s00024-016-1296-x.

Rutkowska, A., Żelazny, M., Kohnová, S., Łyp, M., \& Banasik, K. (2017). Regional L-moment-based flood frequency analysis in the upper Vistula River Basin. Poland: Pure and Applied Geophysics. doi:10.1007/s00024-016-1298-8.

Szymanowski, M., Bednarczyk, P., Kryza, M., \& Nowosad, M. (2017). Spatial interpolation of Ewert's index of continentality in Poland. Pure and Applied Geophysics. doi:10.1007/s00024-0161413-x.

Szymanowski, M., \& Kryza, M. (2017). The role of auxiliary variables in deterministic and deterministic-stochastic spatial models of air temperature in Poland. Pure and Applied Geophysics. doi:10.1007/s00024-015-1199-2.

Vaid, B. H. (2017). Biweekly Sea surface temperature over the South China Sea and its association with the Western North Pacific Summer Monsoon. Pure and Applied Geophysics. doi:10. 1007/s00024-015-1198-3.

Wałaszek, K., Kryza, M., Szymanowski, M., Werner, M., \& Ojrzyńska, H. (2017). Sensitivity study of cloud cover and ozone modeling to microphysics parameterization. Pure and Applied Geophysics. doi:10.1007/s00024-015-1227-2.

Walawender, E., Walawender, J. P., \& Ustrnul, Z. (2017). Geospatial predictive modelling for climate mapping of selected severe weather phenomena over Poland: a methodological approach. Pure and Applied Geophysics. doi:10.1007/s00024016-1250-y.

Werner, M., Kryza, M., Skjøth, C. A., Wałaszek, K., Dore, A. J., Ojrzyńska, H., et al. (2017). Aerosol-radiation feedback and $\mathrm{PM}_{10}$ air concentrations over Poland. Pure and Applied Geophysics. doi:10.1007/s00024-016-1267-2.

Yadav, R. K., \& Singh, B. B. (2017). North equatorial Indian Ocean convection and Indian Summer Monsoon June progression: a case study of 2013 and 2014. Pure and Applied Geophysics. doi:10.1007/s00024-016-1341-9. 